\title{
Linguagens
}

\section{SOBRE O USO DE LITERATURA NA SALA DE AULA DE LÍNGUA INGLESA: PERCEPÇÕES E POTENCIALIDADES}

\author{
André Luís Specht (UNICENTRO) \\ Davi Silva Gonçalves (UNICENTRO)
}

\begin{abstract}
RESUMO: Resistindo a sua própria historicidade e explorando uma linguagem que apela às maiores subjetividades do sujeito, o potencial de formação crítica por parte da literatura nos parece fato consumado. Daí a pergunta: será que, em linhas gerais, existe unanimidade com relação a sua utilização na sala de aula de língua inglesa? E, independentemente disso, será que os caminhos pouco palpáveis da literatura se encaixam nos programas metodológicos atuais? Com o intuito de ao menos tentar sugerir respostas para essas perguntas, o objetivo geral deste trabalho é analisar os discursos de professores de língua inglesa coletados através de um questionário online - que fazem pouco uso da literatura em sala de aula, bem como suas justificativas para isso. Como arcabouço analítico para essa investigação, trouxemos principalmente as contribuições da análise do discurso francesa. Nossa investigação centra-se nas seguintes premissas: 1) a ênfase científica na necessidade e importância do letramento literário está ainda aquém das relações pessoais que os próprios professores estabelecem com a literatura, e 2) certas máximas resultantes de concepções equivocadas de língua tornaram a literatura um objeto pouco convidativo em um contexto "comunicativo". Isto posto, concluímos que os dados interpretados neste estudo demonstram o quanto ainda é conturbada a inserção do gênero literário dentro da sala de aula de língua inglesa.
\end{abstract}

PALAVRAS-ChAVE: Ensino de literatura. Análise do discurso. Ensino de língua inglesa.

\begin{abstract}
Resisting its historicity and exploring a language appealing to one's greatest subjectivities, how literature triggers our critical abilities seems, to us, fait accompli. Hence our qualms: are English language teachers unanimous regarding the usage of literary texts in their classes? Regardless, do the impalpable paths taken by literature fit in current teaching approaches? To suggest how these questions might be answered, the overall purpose of this study is to analyse the discourse of English language teachers - collected through an online questionnaire - who do not use much literature in their classes, as well as their explanations to it. As a main theoretical framework for the investigation, French discourse analysis has been brought. Our investigation is grounded on the following premises: 1) the scientific emphasis on the relevance and applicability of literature teaching still lags behind teachers' personal relationships with the literary genre, and 2) certain maxims resulting from questionable conceptualisations about language and the obsessive idealisation of a communicative context have turned literature into a taboo therein. Having said that, the data collected and interpreted in this study evince how the insertion of literature within the English language classroom is still considerably intricate.
\end{abstract}

KEYWORDS: Literature teaching. Discourse analysis. English language teaching.

Ler é aprender o que e como somos, em toda a nossa humanidade, com nossas ações, nossos sonhos e nossos fantasmas, tanto no espaço público como na privacidade de nossa consciência. Esse conhecimento se encontra apenas na literatura. Nem mesmo os outros ramos das ciências humanas - a filosofia, a história ou as artes - conseguiram preservar essa visão integradora em um discurso acessível, pois também eles sucumbiram ao domínio da especialização. $\mathrm{O}$ elo fraternal que a literatura estabelece entre os seres humanos transcende todas as barreiras temporais. A sensação de ser parte da experiência coletiva através do tempo e do espaço é a maior conquista da cultura, e nada contribui mais para renová-la a cada geração do que a literatura. (LLOSA, 2010, p. 62). 


\section{W Linguagens}

1 INTRODUÇÃO: O ENSINO DE LITERATURA EM "PONTOS DE DERIVA"

Já muito se refletiu acerca da literatura dentro da sala de aula de língua adicional; tema que, portanto, deixou de ser controverso na contemporaneidade, apesar de ainda oferecer uma arena rica de investigações. Essa arena é ocupada, afirma Mortatti (2014, p. 24), principalmente por dois saberes: o literário e o pedagógico: “as relações entre educação e literatura se tornaram temas de discussão e objetos de pesquisa e estudos sistemáticos produzidos por pesquisadores da área dos estudos literários no diálogo crítico com as ciências da educação". Este diálogo teria alavancado o surgimento de novos paradigmas, que vão muitas vezes de encontro com uma visão mais tradicional de língua e literatura (baseada, a citar, na ênfase do ensino de movimentos literários e/ou na utilização do texto literário como fonte para análise gramatical de textos). Em um cenário sociopolítico no qual é evidente a formação crítica do aluno, a contemplação de abordagens nesse sentido passou a permear também o espaço ocupado pela literatura, bem como o papel desempenhado por ela nesse espaço. Cientes do papel desempenhado pelo professor no processo de inserção crítica da literatura em sala de aula, nossas perguntas de pesquisa são as seguintes: (1) até que ponto a utilização ou não da literatura em sala de aula é influenciada pelo interesse que o professor demonstra ter pelo tema?; (2) seria literatura ainda um objeto pouco convidativo para o contexto do ensino de língua, e por que (não)?

Antes de respondermos essas perguntas, entretanto, é importante que partamos de uma das diversas definições de literatura hoje disponíveis. Olher (2008, p. 77) nos disponibiliza uma síntese que faz das definições de literatura de outros pesquisadores, teóricos e escritores: "Se falarmos em termos de senso comum, a literatura é definida como uma coleção de obras de valor real e inalterável que se distingue por certas propriedades comuns. Isto nos remete à literatura como uma entidade ou instituição estável e bem definida". Por mais subjetiva que seja, a definição atende a subjetividade inerente ao mundo literário; devendo o valor real e inalterável da literatura ser compreendido não de forma concreta e/ou idealizada, mas como consequência de sua 


\section{Q Linguagens}

"esteticidade" - ou seja, de sua autodependência para superar as amarras do tempo e espaço, ultrapassando contextos muitas vezes inicialmente adversos a ela. Ficção ou nãoficção, o que muda no texto literário é a agenda: apesar de ser um texto que muito informa, o seu objetivo não é a informação de um conteúdo específico. Nisso, da forma que vemos, o gênero parece diferir de outros gêneros, já que um texto meramente informativo depende diretamente da necessidade ou busca por tal informação. O paradoxo fundador da literatura, por outro lado, é o de que ela terá sempre nos traz conteúdos relevantes justamente por não fazer deste o seu único objetivo: “A literatura é então associada a um valor estético, uma escrita altamente valorativa, ao cânone literário por assim dizer, escrita considerada como de valor que resiste à sua própria historicidade". (OLHER, 2008, p. 78).

Resistindo a sua própria historicidade e explorando uma linguagem que apela às maiores subjetividades do sujeito, o potencial de formação crítica por parte da literatura nos parece fato consumado. Endereçando, através da experiência estética, temas que escapam das amarras materiais do "mundo real", o texto literário se constrói e desenvolve com uma linguagem única - e, em consonância, sua leitura também constrói e desenvolve o leitor de forma única, através dessa linguagem. Trata-se essa, é bom lembrar, apenas de nossa percepção. Daí a pergunta: será que, em linhas gerais, existe unanimidade com relação a ela? E, independentemente disso, será que os objetivos pouco palpáveis da literatura se encaixam nos programas, muitas vezes positivistas, propostos para o ensino de língua adicional na contemporaneidade?

Com o intuito de ao menos tentar sugerir caminhos para responder essas perguntas, bem como para responder as perguntas de pesquisa levantadas acima, encaminhamos um questionário online, contemplando a utilização de literatura em sala de aula, para professores de língua adicional. Coletados os dados, devido à diferença ululante do número de participantes que ensinavam língua inglesa (em comparação com outras línguas, a citar: italiano, espanhol, francês e português para estrangeiros), optamos, neste artigo, por utilizar apenas as respostas destes sujeitos. Além disso, no recorte aqui proposto, o objetivo geral é o de entender, a partir da análise do discurso desses professores, as razões para o baixo uso da literatura em sala de aula. Para isso, levamos em conta apenas aqueles participantes que afirmaram utilizar o texto literário "nunca" ou 


\title{
W. Linguagens
}

"raramente". Tendo selecionado esses participantes, enfocamos em suas respostas dissertativas acerca de sua relação com a literatura e das suas razões para utilizá-la com tal frequência. Como arcabouço analítico para essa investigação, trouxemos as contribuições da análise do discurso, tendo em vista que

\begin{abstract}
Todo enunciado é intrinsecamente suscetível de tornar-se outro, diferente de si mesmo, se deslocar discursivamente de sentido para derivar para um outro (a não ser que a proibição da interpretação própria ao logicamente estável se exerça sobre ele explicitamente). Todo enunciado, toda sequência de enunciados é, pois, linguisticamente descritível como uma série (léxicosintaticamente determinada) de pontos de deriva possíveis, oferecendo lugar a interpretação. (PÊCHEUX, 1997, p. 53).
\end{abstract}

Se todo enunciado é intrinsicamente suscetível de tornar-se outro, é preciso cuidado para lidar com os traços de linguagem, de forma a caminhar com certo equilíbrio sobre as fronteiras entre esses discursos. Isto é, entendendo o recorte aqui analisado como apenas mais um discurso inserido numa panóplia discursiva que vai muito além dele, prescrever certas inconsistências é fácil, assim como aceitar a narrativa principal oferecida também o seria. Por isso, buscando desestabilizar essa lógica estável do discurso através de nossa interpretação analítica, os seus pontos de deriva são explorados de forma tangencial - isto é, refletindo acerca das lacunas discursivas, mas sem o intuito de preenchê-las. Afinal, bem nos lembra Foucault (2012, p. 153), "deve-se entender um conjunto de enunciados, não como a totalidade fechada e pletórica de uma significação, mas como figura lacunar e retalhada". Devido ao nosso anseio por reafirmar e/ou descobrir certas verdades, é nítida nossa idealização dessa totalidade fechada e pletórica dos enunciados. Aceitar a natureza lacunar e retalhada dos discursos é aceitar, também, que nossa interpretação nunca será capaz de abraçá-lo por completo. Por isso, Foucault (2012, p. 154) insiste que a análise do discurso não deve almejar a interioridade utópica das intenções discursivas de um sujeito - sendo o seu pensamento inalcançável (até mesmo para ele); o que nos interessa é a dispersão de sua exterioridade, não sua intencionalidade: "descrever um conjunto de enunciados não implica reencontrar o momento ou a marca de origem, mas sim as formas específicas de um acúmulo". São essas formas específicas de acúmulo, os diversos discursos que um discurso reitera, rearticula e/ou reproduz (na maioria das vezes sem a percepção do sujeito acerca disso 


\section{Linguagens}

tudo) que buscamos analisar. Independentemente das "intenções" de nossos participantes, bem como das verdades superficiais de suas respostas, a análise que segue interpreta suas percepções - e, como qualquer interpretação, a nossa também é passível de ser problematizada, ou, quem sabe, até mesmo reinterpretada futuramente.

\section{METODOLOGIA: IDENTIFICANDO OS DISCURSOS E SUAS "LINHAS DE FUGA"}

Como já indicado previamente, por questões de tempo, espaço e consistência, este artigo consiste em um recorte bastante específico de uma pesquisa maior - cujo corpus consiste nas respostas enviadas por professores de língua adicional acerca do uso de literatura em sala de aula. Originalmente, o formulário conta com 58 preenchimentos, sendo apenas oito deles por professores de outros idiomas (que não o inglês). A pergunta número 9 pede para os professores informarem se utilizam a literatura "sempre", "às vezes", "raramente" ou "nunca" no ensino de língua adicional. Dentre os professores de língua inglesa, $32 \%$ afirmam utilizá-la raramente, enquanto $6 \%$ admitem que nunca tentaram incluí-la em sua metodologia de ensino. Para investigar e analisar as justificativas apontadas por esses $38 \%$ para nunca ou raramente utilizarem a literatura no ensino de inglês, colocamos esse dado em paralelo com as perguntas que o precedem e que o seguem diretamente: "8) Qual a sua relação com a literatura?" e "10) Por que você utiliza o texto literário com essa frequência?". Acreditamos que nos debruçar sobre essas respostas contribui para uma reflexão mais aprofundada acerca da aplicabilidade da literatura na sala de aula de língua inglesa justamente porque "analisar o discurso implica fugir das explicações de ordem ideológica, das teorias conspiratórias da história, de explicações mecanicistas de todo tipo: é dar conta de como nos tornamos sujeitos de certos discursos". (FISCHER, 2003, p. 384). Em anonimato, os participantes ocupam uma arena privilegiada para esboçar suas impressões reais e particulares sobre o tema proposto, sendo o discurso mecanismo excepcionalmente relevante para identificarmos "como certas verdades se tornam naturais, hegemônicas, especialmente de como certas verdades se transformam em verdades para cada sujeito, a partir de práticas mínimas, de ínfimos enunciados, de cotidianas e institucionalizadas regras, normas e exercícios". 


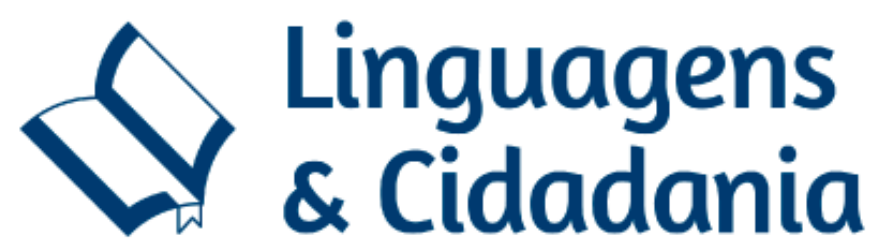

(FISCHER, 2003, p. 385).

Entende-se, portanto, que em geral essas práticas mínimas e ínfimos enunciados compartimentalizados podem naturalizar uma certa narrativa sobre as questões mais variadas - as quais são institucionalizadas através de regras, normas e exercícios não apesar do discurso, mas, na maioria dos casos, exatamente em função dele. É por isso que articular uma análise atenta aos traços que naturalizam certas opiniões implica, ainda de acordo com Fischer (2003, p. 386), "dar conta de possíveis linhas de fuga, daquilo que escapa aos saberes e aos poderes, por mais bem montados e estruturados que eles se façam aos indivíduos e aos grupos sociais". Porém, antes de identificar essas linhas de fuga, bem como para envelopar (ainda que de forma rarefeita) os indivíduos envolvidos nos grupos sociais aos quais parecem pertencer, primeiramente, antes de analisar seus discursos, situamo-nos e historicizamo-nos.

\section{DISCUSSÃO: PROFESSORES E SEUS “REGIMES DE DISCURSIVIDADE"}

Nosso(a) primeiro(a) participante trata-se de um(a) professor(a) bacharel e mestre em Letras - Inglês, pela Universidade Federal de Santa Catarina (UFSC), que leciona aulas particulares de língua inglesa já há mais de dez anos. Sobre sua relação com a literatura: "Quando criança e adolescente, tive pouco contato e interesse. Na graduação e recente mestrado, tenho que fazer muitas leituras. Odeio a literatura do grotesco e ter que ler isso era um sofrimento. Estou amando conhecer a literatura de resistência e de minorias". Essa fala nos leva a entender que o grau de interesse na literatura interfere em sua utilização, já que demonstra um histórico de pouco contato com ela. Ao externalizar que tem de fazer muitas leituras acerca do tema, e expor o sofrimento de ler um gênero que odeia, pode-se notar um sentimento de desagrado com relação à participação compulsória que a literatura tem tido em sua vida. Por outro lado, não fosse essa inserção forçosa, o(a) participante não poderia ter conhecido as literaturas de resistência e de minorias, as quais ele(a) parece apreciar consideravelmente. Talvez a história tivesse sido outra se este sujeito tivesse conhecido esses gêneros antes da pós-graduação, e talvez ela mudasse também se ele(a) fosse mais leniente com relação a literatura.

Isto porque, diversas vezes, nosso juízo de valor pré-determina as particularidades

$$
\text { Linguagens \& Cidadania, v. 20, jan./dez. } 2018 .
$$




\section{Q Linguagens}

daquilo que julgamos - e, no caso da literatura, alguns discursos reciclados tomam corpo, impedindo que alcancemos reflexões mais autônomas acerca dela. "Este juízo de valor está estritamente relacionado ao contexto situacional, às convicções que vamos construindo através do tempo, influenciadas por uma estrutura de crenças evidentes ou ocultas que são, na maioria das vezes, transitórias, ideologias”. (OLHER, 2008, p. 80). É evidente a influência dessas convicções construídas através do tempo no caso da relação com a literatura e, inevitavelmente, nos pressupostos que assumimos sobre os seus atributos e a forma como estes interfeririam ou atrapalhariam a agenda do ensino de línguas: "Textos literários com palavras sofisticadas demais são cansativos e chatos. É preciso escolher bem porque nem todos têm tal nível de conhecimento e abstração". A segunda resposta deste(a) mesmo(a) participante expõe o seu argumento para a dificuldade em inserir a literatura na sala de aula: vocabulário e subjetividade. Questionável? Talvez. Coerente? Diríamos que bastante. Não que os textos sejam cansativos e/ou chatos devido à sua linguagem ou imaterialidade, mas sabemos o quanto é complexa a trajetória para crescimento vocabular e intelectivo, bem como para um "aparelhamento" da abstração (já que capacidade de abstração temos desde muito cedo, talvez inclusive até mais do que no mundo adulto, e as imaginativas brincadeiras infantis são evidência disso). Mora na intricada natureza da literatura a sua capacidade de criar, em nós, novas lentes para percepção do mundo - se ela fosse "mais simples", talvez não fosse tão transformadora.

Ainda segundo este(a) participante: "Comecei a gostar mais de literatura quando fui incentivado(a) a ver a sua relação com a história de um povo em uma determinada época. E também a enxergar sob a perspectiva do colonizado e de minorias". Incentivado(a) a ver a relação da literatura com a história e a enxergar o mundo ao seu redor sob a perspectiva do colonizado coloca esse(a) participante em um processo novo, de (re)conhecimento do que de fato simboliza a experiência literária: uma nova lente estética para apreciação e valoração do real. Essa ambivalência, um discurso que aproxime e afaste ao mesmo tempo certos epistemes, não deve ser entendida como insólita; trata-se de um reflexo direto de nossas identidades que, mais que duais, são inegavelmente polissêmicas. Por isso, em nosso discurso, "as palavras, expressões, proposições, mudam de sentido segundo as posições sustentadas por aqueles que as 


\section{Linguagens}

empregam, o quer dizer que elas adquirem seu sentido em referência a essas posições, isto é, em relação às formações ideológicas". (PÊCHEUX, 1997, p. 160). Mais que as palavras, expressões e/ou proposições selecionadas, nada arbitrariamente, as nossas "verdades" são definidas e sustentadas por essas posições - ainda que suas formações ideológicas, por vezes ignoradas, só possam ser analisadas através dos traços deixados pelo discurso. Os enunciados, afinal, à luz de Foucault (2012, p. 147), "são coisas que se transmitem, se conservam, que têm um valor, e das quais procuramos nos apropriar; que repetimos, reproduzimos e transformamos, para as quais preparamos circuitos preestabelecidos". Nesse sentido, a relevância da literatura parece-nos ainda mais indubitável; afinal, é sempre mais fácil se apropriar, repetir e reproduzir os enunciados hegemônicos, através de nossos circuitos preestabelecidos. De acordo com Vargas Llosa (2010, p. 60), "nada nos protege melhor da estupidez do preconceito, do racismo, da xenofobia, do sectarismo religioso ou político e do nacionalismo excludente do que essa verdade que sempre surge na grande literatura: todos são essencialmente iguais". Democrática por excelência, a literatura oferece-nos circuitos outros, os quais fogem dessas grandes instituições discursivas (religiosas, políticas, nacionalistas etc.) e transgridem aquilo que havia sido conservado, permitindo-nos, assim, crescer enquanto sujeitos, justamente por não se obrigar a dizer-nos absolutamente nada. "Nada nos ensina melhor a ver nas diferenças étnicas e culturais a riqueza do legado humano e a estimá-las como manifestação da multifacetada criatividade humana". (VARGAS LLOSA, 2010, p. $61)$.

Nosso(a) segundo(a) participante já parece estimar a literatura, conforme o apelo de Vargas Llosa (2010). Trata-se, agora, de um(a) professor(a), licenciado(a) em Letras Inglês, também pela UFSC, que leciona há mais de cinco anos em uma escola de idiomas. Ele(a) alega que sua relação com a literatura é grande, e explica: "Minha formação em Letras - Inglês me deu uma base acadêmica bem forte na área de literatura, que se seguiu com meu período no programa de Mestrado em Literatura de Língua Inglesa. Além disso, em minha vida cotidiana, leio livros literários com frequência". Diferente do(a) participante anterior, temos aqui um leitor que se assume assíduo, que afirma consumir a literatura não só no contexto acadêmico como também despretensiosamente, por puro lazer. Apesar disso, ele(a) justifica o pouco uso de literatura na sua prática de ensino de 


\section{Linguagens}

língua inglesa devido ao fato de suas aulas apresentarem "um foco mais comunicativo". Por essa razão, continua: "tendo a utilizar mais textos não-literários com teor mais informativo. Mas em determinados momentos utilizo literatura para trabalhar certos pontos gramaticais, e também para incentivar meus alunos a apreciar literatura”. Bem, dentre aquilo que podemos perceber aqui está o fato de que, para este participante, o caráter comunicativo de suas aulas já, necessariamente, demanda do professor a utilização de outros tipos de textos, que não o literário. A literatura, quando é trazida, serve para refletir acerca de questões gramaticais e, curiosamente, ao mesmo tempo incentivar os alunos a apreciá-la. Curioso justamente porque, para nós, parece difícil imaginar um cenário onde atividades gramaticais com uma obra literária sejam capazes de despertar o desejo do aluno(a) de efetivamente lê-la. Isso nos leva a pensar, portanto, que, ainda que este(a) participante demonstre ter um grande apreço e interesse em literatura, ele(a) carece de artifícios metodológicos para auxiliar seus alunos a compartilharem desse interesse. Além disso, é bem possível que a forma em que este(a) professor(a) tem trabalhado com a literatura em sala venha gerando, na realidade, o resultado inverso.

Nas palavras de Mortatti (2014, p. 30), “o texto literário propicia um trabalho específico de leitura, ao mesmo tempo como fruição estética, que não se deixa controlar, instrumentalizar ou seriar, e como busca de conhecimento que não se restringe à organização e classificação de dados". A leitura de uma obra literária, se diferenciando da "leitura informativa", tem, na fruição estética, seu maior diferencial; e é por isso que trabalhar de forma puramente estruturalista com a linguagem literária nos soa como um desperdício. Por excelência, a literatura "se apresenta como multiplicidade, instaurando outras relações dos sujeitos entre si e com seu passado, presente e futuro, com a cultura e a língua, com o mundo público e o privado”. (MORTATTI, 2014, p. 31). É nesse sentido que, apesar de ser de fato pouco "comunicativa", no sentido literal da palavra, o texto literário possibilita uma construção de pontes entre cultura e língua, passado e futuro, público e privado que, talvez, pudessem ser melhor aproveitadas em sala de aula. Aparentemente, entretanto, ainda que o tema ensino de literatura venha sendo explorado nos contextos acadêmicos, em termos metodológicos ele ainda representa um desafio.

Também nos passa essa impressão o que alega o(a) terceiro(a) participante, formado(a) em turismo pela Universidade Federal do Paraná (UFPR), com Mestrado em 


\section{W. Linguagens}

Letras na Universidade Federal de Santa Catarina (UFSC), e professor(a) de língua inglesa em uma escola de idiomas (tendo começado a lecionar entre um e cinco anos atrás). Ainda que ele(a) afirme gostar de ler, ele(a) justifica que a literatura tem pouco espaço em suas aulas: "Porque seleciono uma pluralidade de gêneros, dentre outros tipos de atividades que não são de leitura (speaking, writing, reading, grammar, vocabulary). Por isso, não há tempo hábil para textos literários". Ou seja, apesar de selecionar uma pluralidade de gêneros para suas aulas, a literatura parece ocupar um lugar periférico em comparação com os outros. A falta de tempo hábil para textos literários se deve à ideia equivocada de que eles serviriam apenas para atividades de leitura. Ora, originalmente, a literatura foi um gênero muito mais oral e coletivo do que, talvez, qualquer outro gênero textual. Obras do gênero dramático, por exemplo, inerentemente performático, representam, da forma que vemos, uma boa oportunidade de se trabalhar com diversas habilidades utilizando um mesmo material. Além disso, vemos hoje, também, uma certa "modernização" da literatura com os audiobooks, adaptações cinematográficas e animações, que podem ser utilizados para trabalhar com o desenvolvimento de habilidades de escuta.

É bem verdade, por outro lado, que "as mudanças políticas, a evolução das sensibilidades, as mutações tecnológicas conturbaram os regimes de discursividade das sociedades ocidentais contemporâneas". (COURTINE, 1999, p. 12). Talvez, perante essas nossas novas sensibilidades, os regimes de discursividade concernentes à literatura possam ter redirecionado ideias de interconectividade, multidisciplinaridade e amplitude para outros polos, supostamente menos limitados. Interessante, nesse sentido, é a fala de nosso(a) próximo(a) participante, licenciado(a) em Letras em uma faculdade estrangeira e professor(a) particular de inglês há menos de cinco anos. Quanto a sua relação com a literatura, este(a) diz gostar, ainda que seja "um casamento arranjado" - o que deixa a nítida impressão de que existe, novamente, algum grau de obrigatoriedade nisso. Já com relação à utilização do gênero em suas aulas, o(a) participante afirma que ela "não se adequa às necessidades do aluno"; pressuposto nisso está não só a ideia de que o professor tem plena consciência de quais seriam essas necessidades, como também uma visão mais pragmática com relação ao ensino de língua - pragmatismo que, por toda a abstração que ela implica, é apenas tangenciado pela literatura. $\mathrm{O}(\mathrm{A})$ participante se justifica: "Os

\section{Linguagens \& Cidadania, v. 20, jan./dez. 2018.}




\section{Singuagens}

alunos querem algo mais concreto, principalmente se lembrarmos da definição, por nós, feita. Outro fator crucial é que esses aprendizes geralmente vêm das chamadas ciências exatas. Usar as metáforas de Baudelaire não vai fazer o carrinho avançar muito". Ou seja, aqui a suposta incapacidade ou desinteresse nos alunos em explorar a subjetividade da literatura seria consequência não de sua idade e/ou maturidade, mas do fato que a maior parte deles vem das ciências exatas. Por esse motivo, ao que tudo indica, eles querem algo mais palpável do que talvez pudessem querer os alunos de ciências humanas. Realmente, a literatura pouco teria a fazer em um ensino instrumentalizado de inglês; e é nesse sentido que nossa concepção de leitura e de ensino é capaz de indicar também nossa própria concepção de língua.

De acordo com Olher (2008, p. 82), "não existe um receptor ou leitor préestabelecido, como se quer crer, mas sim que o que existe dentro da obra e o que a ela diz respeito são fatores importantes para 'produzir' o leitor. Este leitor é formado, instruído, construído e até manipulado pela obra”. Nesse sentido, não haveria uma área específica que faria da literatura mais ou menos aplicável, já que é ela a responsável por criar essa aplicabilidade. "O leitor é inventado pela obra literária e, por consequência, a obra passa a ser então uma instituição, formando assim seus próprios leitores, dando-lhes competência e "performance'”. (OLHER, 2008, p. 83). Metodologicamente evitada, ou pragmaticamente questionada, a natureza performática da literatura parece consistir ainda em um mistério dentro da sala de aula. Nada de novo nisso; em um contexto educativo que se torna gradativamente mais produtivista, reducionista e positivista, a arte como um todo vem tendo menos espaço. Sem perceber, afetados por esse contexto, muitas vezes o reproduzimos e normalizamos em nosso discurso. É nesse sentido que a análise do discurso nos permite compreender também "como determinados discursos vão se configurando em meio a relações de poder e questionar as condições de possibilidade a partir das quais determinados discursos concorrem para o exercício do poder e a produção de subjetividades”. (ALVES; PIZZI, 2014, p. 87). Convencidos, devido a essas relações de poder, de que os textos literários trazem poucas respostas para a sala de aula, deixamos de lado sua habilidade em nos fazer formular perguntas - processo esse que, talvez, mais desenvolva nossa capacidade crítica. Mortatti (2014, p. 31) enfatiza esse papel subjetivo, mas não menos relevante, dos livros: "lendo-os, aprendemos algo sobre nossa vida, ao 


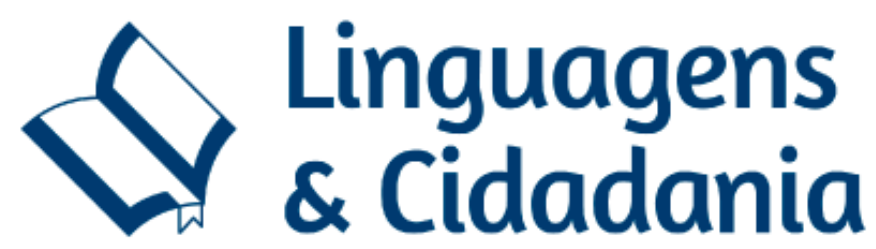

mesmo tempo em que aprendemos sobre a importância da literatura na formação do ser humano; esses textos têm, portanto, uma função formativa específica". Tal função é algo que de fato nós, professores, precisamos assimilar.

Nosso(a) quinto(a) participante, mestre e graduado(a) em Secretariado pela Universidade Estadual de Maringá (UEM), potencializa essa reflexão. Nesse caso, o(a) professor(a), que ministra no contexto acadêmico há mais de dez anos, afirma: "Pouca. Leio nos momentos livres, mas gosto de saber sobre diferentes perspectivas da literatura". Interessante notar que, apesar de ter pouco tempo para a leitura, esse participante busca oportunidades de saber diferentes perspectivas sobre a literatura, ainda que não consiga consumi-la efetivamente. Segundo ele(a), isso também deve-se por trabalhar "em um curso no qual não há afinidade com a literatura". Mas então por que seria interessante conhecer a teoria que a envolve? Será que lecionar no contexto acadêmico é algo que nos "pressiona" a entender quais as perspectivas literárias? Será que acabamos nos "intelectualizando" demais nesse sentido enquanto esquecemos o principal, que é a apreciação da obra literária? Nas palavras de Foucault (2012, p. 118), "um enunciado tem sempre margens povoadas de outros enunciados"; margens essas que permanecem obscuras e foscas, mas nunca invisíveis. A falta de tempo para a literatura, bem como a compartimentalização dos potenciais leitores das áreas de exatas, biológicas e humanas, está diretamente relacionada à vida moderna, que tem na especialização um de seus motores mais pungentes. "A especialização traz benefícios, pois possibilita pesquisa e experimentos e é a força motriz do progresso; mas ela também destrói os denominadores comuns culturais que permitem a coexistência, a comunicação e a solidariedade". (LLOSA, 2010, p. 60). Separados em guetos com identidades particularizadas, acabamos nos esquecendo desses denominadores comuns à nossa (co)existência; e, metaforicamente, Llosa (2010, p. 61) adverte que vamos nos concentrando "tanto na folha, a ponto de esquecer que ela é parte da árvore - e esta, da floresta”. Sem metáfora, Souza e Cosson (2013, p. 106) alegam mais ou menos o mesmo em sua defesa do letramento literário na sala de aula, cujo objetivo seria formar "um leitor capaz de se inserir em uma comunidade, manipular seus instrumentos culturais e construir com eles um sentido para si e para o mundo em que vive".

Ciente deste potencial, mas também da dificuldade de explorá-lo no contexto 


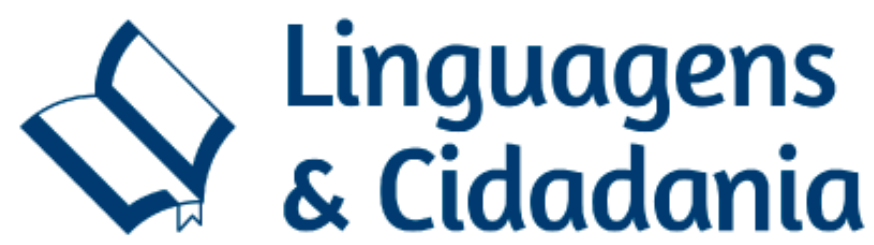

escolar está o(a) próximo(a) participante, licenciado(a) e mestre em Letras, pela Universidade do Estado da Bahia (UNEB), e professor(a) de inglês para o ensino fundamental em uma escola pública há menos de cinco anos. Ele(a) afirma: "Além de ser leitor(a) de literatura, utilizo o referencial teórico para analisar literatura na análise de outras linguagens como quadrinhos e cinema". Em outra resposta, o(a) participante reitera essa preferência por trabalhar com quadrinhos e cinema em sala de aula, por achar mais fácil e cabível ao contexto; e, de fato, as contribuições da análise literária muito podem dar luz para a leitura e apreciação de materiais os mais diversos. Por sinal, "é a forma que o público trata ou considera a literatura que torna um texto 'literário', é a maneira como lemos o texto e não sua natureza que define o que é literatura”. (OLHER, 2008, p. 80). E por "texto" podemos entender também não só os quadrinhos e o cinema, citados pelo(a) participante, como também séries, notícias, documentários etc., que podem ser apreciados esteticamente e analiticamente pelas lentes da análise literária. Existem riscos, entretanto, nessa transição do corpus apreciado, e deles nos lembra Vargas Llosa (2010, p. 66), ao postular que "o desenvolvimento da mídia audiovisual, ao mesmo tempo que revoluciona as comunicações, monopoliza cada vez mais nosso tempo, relegando a leitura a segundo plano". Nesse sentido, o crescente interesse na análise literária de mídias audiovisuais não é em si problemático - ao menos não pelo objeto analisado; o que preocupa é nossa também crescente inabilidade em digerir narrativas mais longas: livros, propriamente ditos. Fato este que "permite-nos imaginar para um futuro próximo uma sociedade moderníssima, repleta de computadores, telas e microfones, mas sem livros. Temo que esse mundo cibernético seja profundamente incivilizado, sem espírito, apático: uma resignada humanidade de robôs". (VARGAS LLOSA, 2010, p. 67). Um tanto apocalíptico, o cenário descrito não está tão distante da atual apatia e resignação perante literatura:

Na educação básica, a situação precária que o ensino de LE, e não somente este componente, se encontra pouco permite a utilização das literatura clássica [sic.], o máximo que usamos são amostras com fragmentos de obras literárias dos livros didáticos e pequenas narrativas e poemas - também presentes nos livros didáticos. Os discentes não têm acesso a este tipo de material fora da sala de aula pois não temos biblioteca funcionando na escola - privando-o ainda da literatura brasileira e portuguesa - e a impressão do material está restrita a cópias das avaliações de final da Unidade. 


\section{W. Linguagens}

Essa fala, do(a) mesmo(a) participante, sugere que trabalhar com literatura "clássica" é inviável na educação básica devido à precariedade da estrutura, física e curricular, da instituição escola. $\mathrm{O}(\mathrm{A})$ participante afirma, ainda assim, explorar os aspectos literários de fragmentos e poemas disponíveis nos livros didáticos. $\mathrm{O}$ foco no livro didático é justificado pelo fato dos discentes não terem meios de encontrar, fora dele, outras narrativas. Seria, talvez, de fato utópico supor que a literatura pode ser explorada em sua mais ampla totalidade em escolas onde não há uma biblioteca, ou onde o(a) professor(a) teria de imprimir os textos literários com o dinheiro do próprio bolso. Entretanto, é também verdade que a literatura tem mais a ver com nossa percepção do que com o objeto percebido; por isso às vezes, em nosso discurso, reafirmamos certas "dificuldades" que podem ou não estarem presentes, dando atenção em demasia para os obstáculos e perdendo de vista as potencialidades menos óbvias. Nesse sentido, o fato de que os alunos não têm acesso ou hábito de ler literatura fora de sala de aula evidencia a sua necessidade, e não o contrário. Se é apenas na escola que eles podem desenvolver uma apreciação crítica do mundo literário, é, talvez, justamente lá que deveríamos tentar ensiná-los. $\mathrm{O}$ ensino público, de literatura ou não, afunda-se nas margens da sociedade contemporânea, esquecido pelo governo e cada vez mais descreditado pelo resto da população. Devemos, por outro lado, resistir a esse processo, ainda que, compreensivelmente, nosso discurso desvele também o derrotismo de quem atua dentro desse contexto. Isto é, no discurso que assumimos, "podemos encontrar mecanismos de subjetivação e as táticas das relações de poder que excluem outras possibilidades discursivas, seja interditando, rejeitando ou separando o verdadeiro do falso, ou fazendo tudo isso de uma só vez". (ALVES; PIZZI, 2014, p. 83). Nós, da rede pública de ensino, precisamos sempre nos forçar para evitar essa exclusão de possibilidades discursivas mais ambiciosas; pois o projeto, a longo prazo, é justamente que até nós desistamos delas.

$\mathrm{O}$ (A) sétimo(a) e último(a) participante, licenciado(a) e bacharel em Letras pela UEM, é professor(a) de inglês há menos de cinco anos em uma escola de idiomas. Sua relação com a literatura, afirma, foi curta e "muito superficial, lia apenas durante a graduação". Curta é também sua justificativa para não a utilizar em suas aulas de inglês: "Devido à metodologia da escola e materiais". Novamente podemos talvez estabelecer 


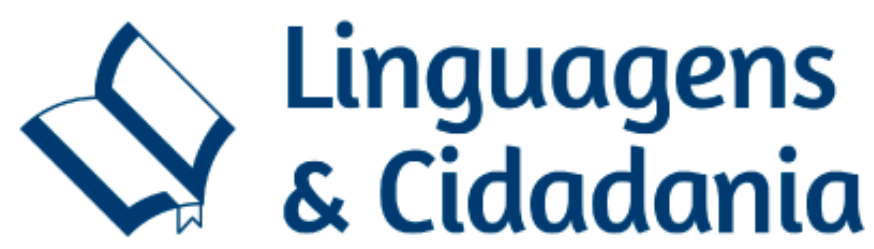

esse traço entre a falta de interesse do(a) professor(a) na literatura, bem como o impacto que isso pode vir a ter em seu interesse por tentar inseri-la em sua prática profissional. Mais uma vez, também, é levantado o estranhamento que a literatura poderia causar em um ambiente de ensino cuja metodologia, material e estrutura não parecem incluí-la. Mas que metodologia é essa? Seria a abordagem comunicativa? E, se sim, por que a literatura não pode estar entre os citados materiais? São perguntas que permanecerão sem resposta, a não ser hipotéticas. Possivelmente, por não representar um papel formador na vida desse participante, dos seus alunos e dos próprios administradores da escola, a literatura não é compreendida como fundamental, prática e aplicável ao contexto onde a língua é ensinada. A literatura, seguindo esse raciocínio, serviria apenas para "dar prazer"; ainda que, conforme outras respostas, aparentemente nem isso ela venha fazendo direito. O que devemos evitar, de acordo com Vargas Llosa (2010, p. 59), é a ideia simplificada de "literatura como passatempo em prol de considerá-la, além de uma das ocupações mais estimulantes e enriquecedoras do espírito humano, uma atividade insubstituível para a formação de cidadãos na sociedade moderna e democrática". Desafios metodológicos, dificuldades estruturais, aplicabilidade comunicativa: todas essas são questões que, efetivamente, ainda precisam ser colocadas em teste com relação ao ensino de literatura. Independentemente disso, corroboramos com a ideia de que "ela deveria ser semeada nas famílias desde a infância e fazer parte de todos os programas educacionais". (VARGAS LLOSA, 2010, p. 59). Alguns "porquês" já sabemos; falta o "como" ser investigado com mais destreza, bem como ser metodologicamente desenhado.

\section{CONSIDERAÇÕES FINAIS: A "PROLIFERAÇÃO INTERNA DE SENTIDOS"}

Inserida no âmbito da análise do discurso, a análise apresentada, obviamente, deve ser relativizada: afinal, trata-se de uma interpretação na qual os regimes de discurso dos próprios interpretes, nós, desempenha papel fundamental. Talvez seja essa nossa maior limitação: já possuir um olhar sobre aquele olhar que analisamos, por mais que tentemos evitar qualquer tipo de interferência. Em termos práticos, o estudo buscou o estabelecimento daquilo que Alves e Pizzi (2014, p. 85) chamam "lei de raridade", definida por quatro aspectos: "o primeiro é o de que os enunciados, por mais numerosos 


\section{Singuagens}

que sejam, não dão conta de dizer tudo o que é possível; ou seja, eles estão sempre em déficit com o campo das formulações possíveis". Aquilo que foi dito e interpretado, poderia sempre ser colocado de outra forma; então, por mais simples que qualquer das respostas expostas possa parecer, elas são raras, únicas. "O segundo diz respeito à definição de um sistema limitado de presenças, o que implica analisar os enunciados no limite do que não está dito, nos processos pelos quais outros possíveis enunciados são excluídos". (ALVES; PIZZI, 2014, p. 86). Isto é, por mais multifacetado que o discurso possa parecer, ele não pode significar qualquer coisa - assim como nunca significa apenas uma. "O terceiro é que essa exclusão não quer dizer que um enunciado tome o lugar de outro, porque cada enunciado tem o seu lugar próprio". (ALVES; PIZZI, 2014, p. 86). É nesse sentido que o discurso não é substituível pelos sentidos que nele se escondem, pois estes sentidos só existem justamente pela maneira particular em que estão ali velados. Finalmente, "o último aspecto é o de que, apesar de os enunciados parecerem tão evidentes por serem transmitidos e conservados, eles não são transparentes nem têm um único sentido". (ALVES; PIZZI, 2014, p. 86). Por conta disso, compreender a complexidade do discurso, desse modo, seria aceitar o fato de que até mesmo nossa interpretação acerca dele terá outras acepções, dependendo da forma como for transmitida e/ou conservada. Isto posto, os dados que interpretamos neste estudo demonstram que ainda é conturbada a inserção do gênero literário dentro da sala de aula de língua inglesa.

É verdade, por outro lado, que sua relevância parece estar sendo debatida dentro dos cursos de formação dos professores, ainda que timidamente. Entretanto, é possível inferir, a partir das respostas analisadas, que essa reflexão se complica por detalhes significativos. Um deles parece ser o fato de que a utilização do gênero ainda carece de estratégias metodológicas mais claras: ainda que alguns professores "aceitem" (talvez por uma certa pressão) a importância da literatura, muitos se mostram confusos na hora de pensar a sua utilização em sala. Outro detalhe é o fato de que muitos professores, simplesmente, não gostam de literatura - e, se não gostam, não a leem; e, se não a leem, não a vivem, o que dificulta ainda mais que sua função seja compreendida e aplicada durante suas aulas. Negligenciada no cotidiano atribulado da sociedade moderna, a arte ocupa um segundo plano - e a literatura, como objeto estético, perde seu sentido de ser caso não seja apreciada desse modo. Instrumentalizada, ela perde a sua própria razão de 


\section{Linguagens}

ser e, em um cenário educacional muitas vezes obsessivo com "o mundo real”, uma pitada de abstração poderia fazer bem, por mais deslocada que ela possa parecer. Quando reiteramos, em nosso discurso, essa visão mais rasa e conteudista de língua - e até mesmo do ensino como um todo - agimos em conformidade com o status quo, que prefere mentes ocupadas a mentes pensantes. Segundo Foucault (2012, p. 147), “o discurso é um bem finito, que tem suas regras de aparecimento e também suas condições de apropriação e de utilização; um bem que coloca em evidência a questão do poder; um bem que é, por natureza, o objeto de uma luta, e de uma luta política". Cada uma das falas aqui discutidas é permeada pela questão do poder, indicando a luta política que ainda ocupa as entrelinhas do discurso sobre a literatura. Alterar o nosso discurso sobre a aplicabilidade e função do texto literário consiste, nesse sentido, em um passo fundamental para que até mesmo a nossa concepção acerca da literatura possa ser rearticulada. Afinal, como bem sugerem as palavras de Olher (2008, p. 83), “a literatura representa aquilo que se diz dela, um significante através do tempo, significando 'nada' por se tratar de algo evanescente ou vazio, seu 'ser' está na significação e não em seus supostos significados”.

A arte, carro-chefe na defesa do vazio, serve em muito para lembrar-nos de que o próprio objeto mundo pode e deve ser observado esteticamente, analisado em sua subjetividade, interpretado conforme nossas perspectivas e não pré-concebido pelos outros discursos e canais discursivos que as circundam. $\mathrm{Na}$ vida vertiginosa das novas tecnologias, das máquinas, da comunicação, na busca cada vez mais incessante pelo instantâneo, pela experiência fugaz, pela natureza mais efêmera das coisas, a literatura se faz urgente. Mortatti (2014, p. 29) aponta essa necessidade, indicando que o texto literário é um dos poucos meios capazes de nos forçar a largar um pouco os objetos que acumulamos, para então olharmos novamente para eles - da forma menos ambivalente possível: "A literatura não corrompe nem edifica, mas, trazendo livremente em si o que chamamos o bem e o que chamamos o mal, humaniza em sentido profundo, porque faz viver". Vivemos cultura, vivemos nossas tradições, vivemos a literatura e, claramente, vivemos também a nossa língua. Não há, desse modo, como separar em nichos essas questões que compõem a nossa própria estrutura humana, o nosso próprio e simples viver. Por isso, e por mais compreensível possa parecer utilizá-la nunca ou raramente no contexto de ensino de línguas, não podemos desistir da literatura, mas, sim, destrinchar 


\section{Linguagens}

suas contribuições e definir planos para sua (re)inserção neste contexto. É essa a mudança que se faz necessária, "porque toda boa literatura é um questionamento radical do mundo em que vivemos; qualquer texto literário de valor transpira uma atitude rebelde, insubmissa, provocadora e inconformista". (LLOSA, 2010, p. 64). Precisamos apenas olhar ao redor e ver a situação social e política na qual nosso país se encontra para entender o quanto esse questionamento radical se faz necessário. Mais do que alunos simplesmente aptos para se comunicar em inglês, precisamos também que eles incorporem essa atitude rebelde, insubmissa, provocadora e inconformista que só a literatura lhes pode dar. Vargas Llosa (2010, p. 65) conclui, e nós concluímos com ele: "sem a literatura, a mente crítica - verdadeiro motor das mudanças históricas e melhor escudo da liberdade - sofreria uma perda irreparável”.

\section{REFERÊNCIAS}

ALVES, J.; PIZZI, L. Análise do Discurso em Foucault e o Papel dos Enunciados. Revista Temas em Educação, v. 23, n. 01, 2014. p. 81-94.

COURTINE, J. J. O discurso inatingível: marxismo e linguística. Trad. Heloisa Monteiro Rosário. Cadernos de Tradução, n. 06, 1999.

FISCHER, R. M. B. Foucault revoluciona a pesquisa em educação? Perspectiva, v. 21, n. 02, 2003. p. 371-389.

FOUCAULT, M. A arqueologia do saber. Rio de Janeiro: Forense Universitária, 2012.

MORTATTI, M. do R. Na história do ensino da literatura no Brasil: Problemas e possibilidades para o século 21. Educar em Revista, n. 52, 2014. p. 23-43.

OLHER, R. M. Literatura e Instituição. Anuário de Literatura, v. 13, n. 02, 2008. p. 76-85.

PÊCHEUX, M. O discurso: estrutura ou acontecimento. Trad. Eni Orlandi. 2 ed. Campinas, SP: Pontes, 1997.

SOUZA, R.; COSSON, R. Letramento literário: uma proposta para a sala de aula. São Paulo: UNESP/UNIVESP, 2013.

VARGAS LLOSA, M. A importância da literatura. Substantivo Plural. Outubro, 2010. 


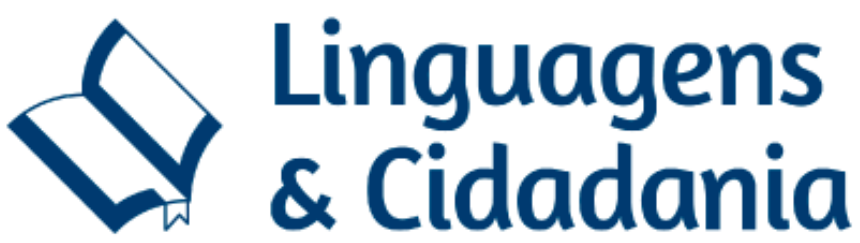

p. $58-68$.

Linguagens \& Cidadania, v. 20, jan./dez. 2018. 